\begin{tabular}{c} 
International Journal of Engineering \& Technology, $7(3)(2018)$ 1059-1062 \\
International Journal of Engineering \& Technology \\
SPC \\
Website: $\begin{array}{c}\text { www.sciencepubco.com/index.php/IJET } \\
\text { doi: } 10.14419 / \text { ijet.v7i3.13155 } \\
\text { Research paper }\end{array}$ \\
\hline
\end{tabular}

\title{
Simulation, design of unequal five way wilkinson power divider for $\mathbf{E W}$ applications
}

\author{
M. Siva Charan ${ }^{1}$ *, Praveen Vummadisetty. Naidu ${ }^{1}$, A. Rajasekhar ${ }^{1}$, Gaurav Bansod ${ }^{3}$, \\ P. Raveendra ${ }^{1}$, Arvind Kumar ${ }^{2}$ \\ ${ }^{1}$ Velagapudi Ramakrishna Siddhartha Engineering College, Vijayawada, India-520007 \\ ${ }^{2}$ K.I.T.E, Jaipur, India-302022 \\ ${ }^{3}$ PICT, Pune-411043, India \\ *Corresponding author E-mail: sivacharan27@gmail.com
}

\begin{abstract}
This paper deals with the design and simulation of unequal 5-way Wilkinson power divider used for Electronic Warfare (EW) applications. The frequency range of operation intended for this design is $6 \mathrm{GHz}$ to $18 \mathrm{GHz}$. The proposed Wilkinson power divider is designed on a low cost FR-4 substrate having height of $1.5 \mathrm{~mm}$, relative permittivity of 4.4 and loss tangent of 0.02 . The design occupies a size of $11 \mathrm{~mm} \times 33 \mathrm{~mm} \times 1.5 \mathrm{~mm}$. Equal split Wilkinson power dividers are utilized for implementation of this design. High isolation has been obtained throughout the frequency range of $6 \mathrm{GHz}$ to $18 \mathrm{GHz}$. The design procedure is discussed. The simulated results are presented by using ADS simulation software.
\end{abstract}

Keywords: Wilkinson Power Divider; Micro Strip; ADS; FR-4.

\section{Introduction}

The research on printed multiband/wideband antennas [10-17] and [20-41] and array antennas [18-19] have grabbed lot interest to the design engineers. Power dividers [1-9] are passive devices that are widely used in RF (Radio Frequency) subsystems and also find application in Microwave environments. Corporate feed with power dividers is often employed in antenna arrays [18-19]. The purpose of a power divider is to split a given input signal and it can also be used reciprocally to combine multiple signals. The main criteria required for power dividers are reciprocity being lossless and being matched at all ports and also to provide better isolation. The N-Way Power divider was described by Wilkinson in 1960 [1]. But the cylindrical shape presented in the design may not be suitable for all applications. Unequal power split is often required when realizing dividers with more than three ports [2]. The conventional Wilkinson power divider provides narrow isolation bandwidth. So in [3] Multistage Power dividers presented for improved bandwidth is discussed. At higher frequencies, the length $\lambda / 4$ (90 degrees) is not sufficient to curve the branches. To get around this $3 \lambda / 4$ (270 degrees) can be used [4].Also, at lower frequencies hybrid designs involving port extensions to Wilkinson power divider [5] and lumped element isolation networks [6]- [8] are proposed. At higher frequencies the topologies involving complex isolation networks using $\mathrm{R}, \mathrm{L}$ and C's find limited usage due to parasitic effects. A small size wide band unequal Wilkinson power divider is reported in [9]. Below in Figure 1 is the standard Wilkinson power divider when $\mathrm{N}=$ two [1].

In article, the proposed design makes use of equal split Wilkinson power divider design (WPD). A modified 3-way is presented with one less isolation resistor when compared to [1]. The 2-way is a normal equal split power divider with no modifications. Overall, one 3-way WPD and two 2-way WPD are used in the proposed design.

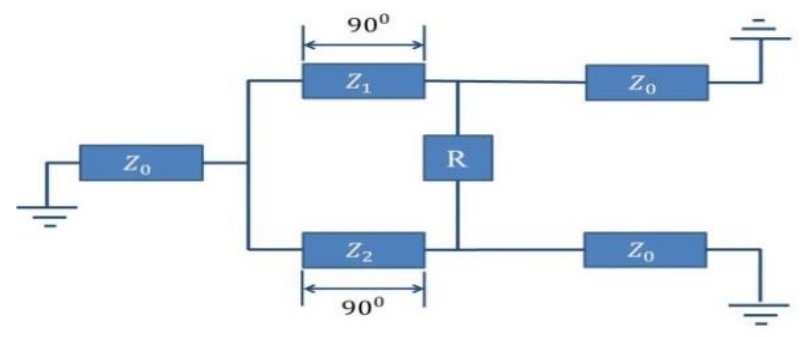

Fig. 1: Schematic Model for Wilkinson Power Divider.

\section{Design of unequal 5-way power divider}

The power divider is realized using microstrip. The substrate used is FR4 with substrate height $1.5 \mathrm{~mm}$ and thickness of conductor of $0.016 \mathrm{~mm}$. In this a modified 3-way, 2-way Wilkinson power dividers are used. The required impedances are in Figure 2. The impedance values are calculated from [1], [2] and the equations (1)-(5) required are given.

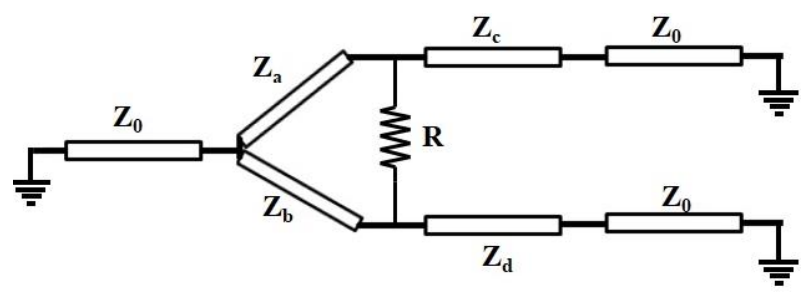

Fig. 2: Schematic Model for Unequal Wilkinson Power Divider. 


$$
\begin{aligned}
& Z_{a}=Z_{0} \sqrt{K\left(1+K^{2}\right)} \\
& Z_{b}=Z_{0} \sqrt{\left(\frac{1+K^{2}}{\mathrm{~K}^{3}}\right)} \\
& Z_{c}=Z_{0} \sqrt{K} \\
& Z_{d}=\left(\frac{Z_{0}}{\sqrt{K}}\right) \\
& R=Z_{0}\left(\frac{1+K^{2}}{K}\right)
\end{aligned}
$$

Where ' $\mathrm{Z}_{0}$ ' is the system impedance. ' $\mathrm{K}$ ' is power split ratio. ' $\mathrm{R}$ ' is Isolation resistor.

Since $6 \mathrm{GHz}$ to $18 \mathrm{GHz}$ is the chosen frequency band for the operation of power divider, a center frequency of $12 \mathrm{GHz}$ is chosen, which is used as design frequency to compute impedance and phase length. The calculations are performed through use of ADS MLIN tool. After placing them they are further tuned and optimization algorithms in ADS are used to get required characteristics. A layout is designed based on the impedances and lengths calculations. The layout is simulated on ADS Momentum simulation tool to get EM simulation data. The EM data is used for further simulation with resistor values. The block representation of the design is given in the Fig 3 and the layout of modified 2-way is presented in Figure4, modified 3-way is presented Figure 5 and the overall 5way is presented in Figure 6.

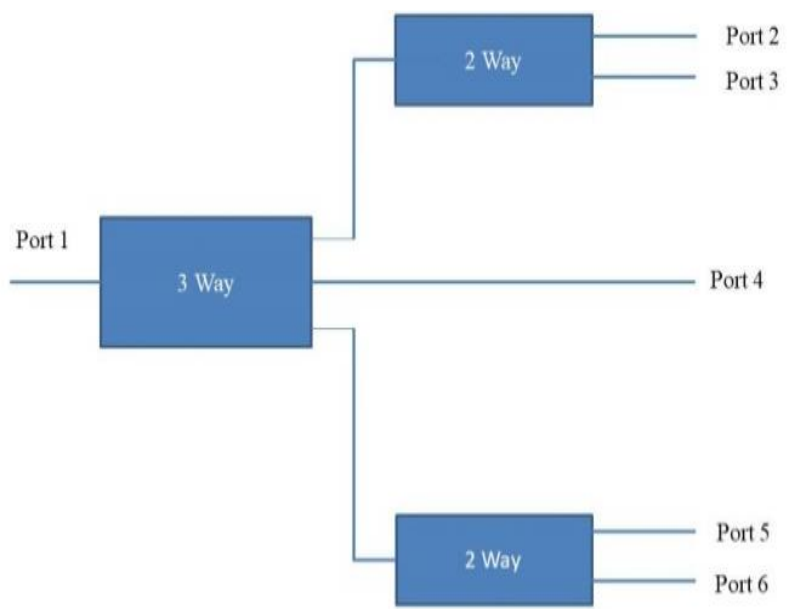

Fig. 3: Block Diagram for Proposed Design.

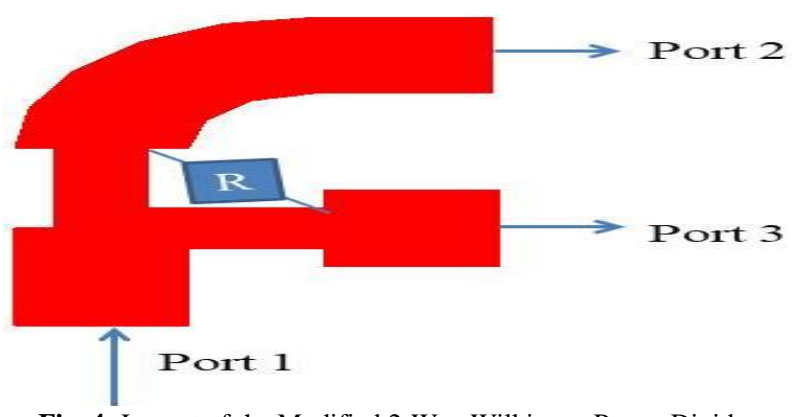

Fig. 4: Layout of the Modified 2-Way Wilkinson Power Divider

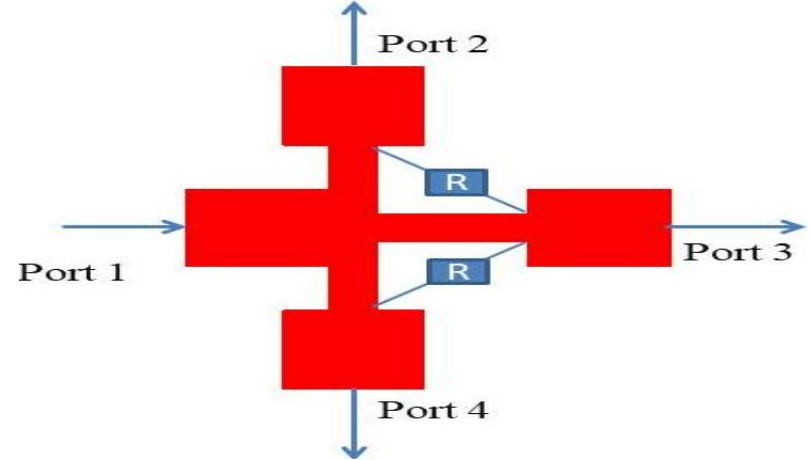

Fig. 5: Layout of the Modified3-Way Wilkinson Power Divider

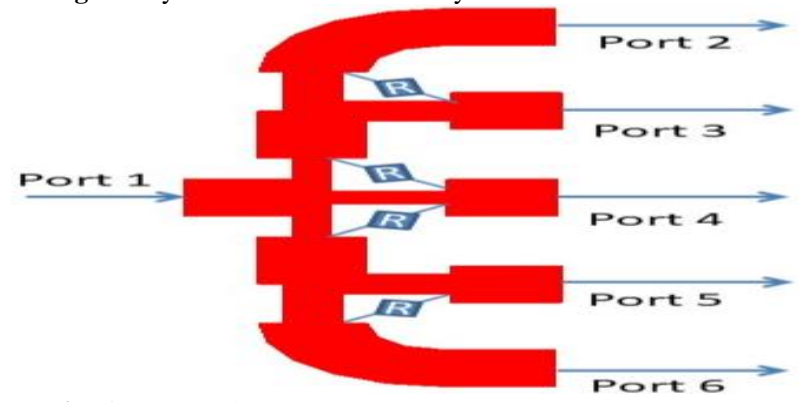

Fig. 6: Layout of the Unequal 5-Way Wilkinson Power Divider.

Here ' $\mathrm{R}$ ' isolation resistor is taken as $50 \Omega$ after tuning in the ADS design tool.

\section{Simulated results}

The results are simulated using ADS 2016.01 and are presented below. The return loss data of all the ports is given in Figure 7, isolation between output arms is given in Figure 8 and insertion loss is given Figure 9.

The return loss obtained is nearly below $-10 \mathrm{~dB}$ across the whole frequency range of $6 \mathrm{GHz}$ to $18 \mathrm{GHz}$ and at centre frequency of $12 \mathrm{GHz}$ we obtain about $-20 \mathrm{~dB}$ on average across all ports. The isolation between all the output ports over the entire frequency of operation is below $-10 \mathrm{~dB}$ and at centre frequency we obtain about $-20 \mathrm{~dB}$ average isolation. From $8 \mathrm{GHz}$ to $17 \mathrm{GHz}$ at least $-15 \mathrm{~dB}$ of isolation is obtained. The insertion loss is different for port 4 and remaining ports due to the fact that port 4 is direct output from the 3-way power divider whereas others are outputs from 2-way power dividers. So, we get lower insertion loss of about $-5 \mathrm{~dB}$ at port 4 and at other ports average of $-13 \mathrm{~dB}$ is observed at centre frequency of $12 \mathrm{GHz}$. This can be attributed to equal power split of 3-way power divider which results in 2 -way getting $(1 / 3)^{\text {rd }}$ of the total power. This can be adjusted by means of changing the impedance on the output arms of the 3-way power divider.

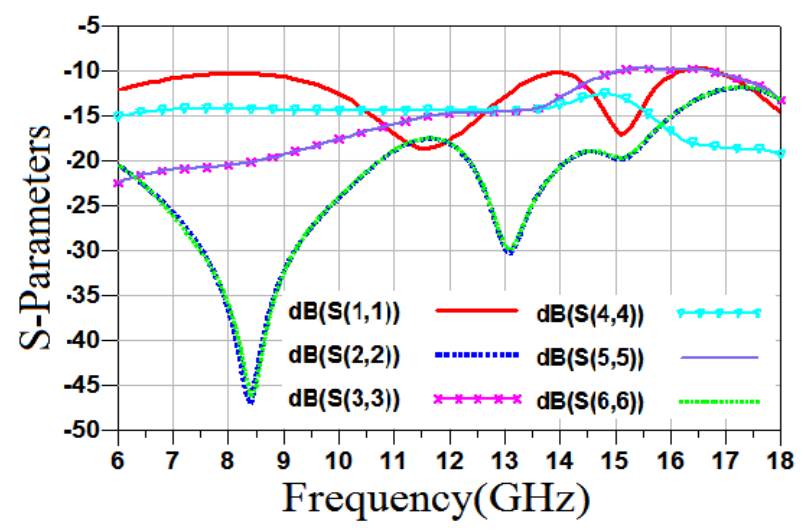

Fig. 7: Return Loss of the Proposed Design. 


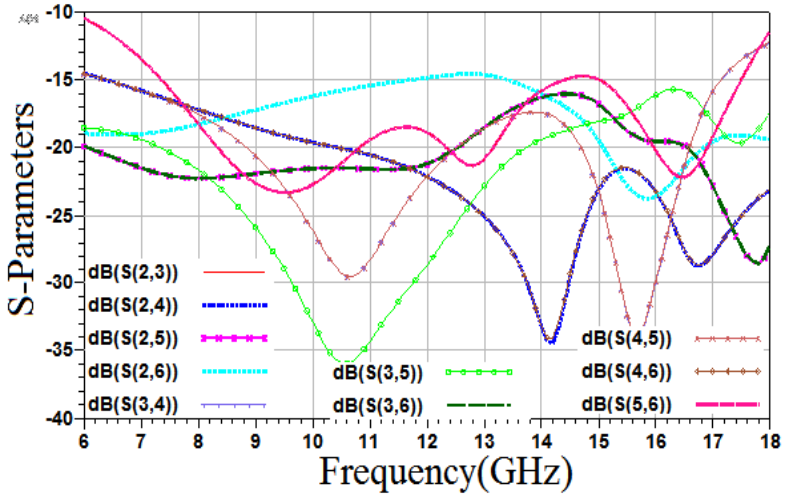

Fig. 8: Isolation of the Proposed Design

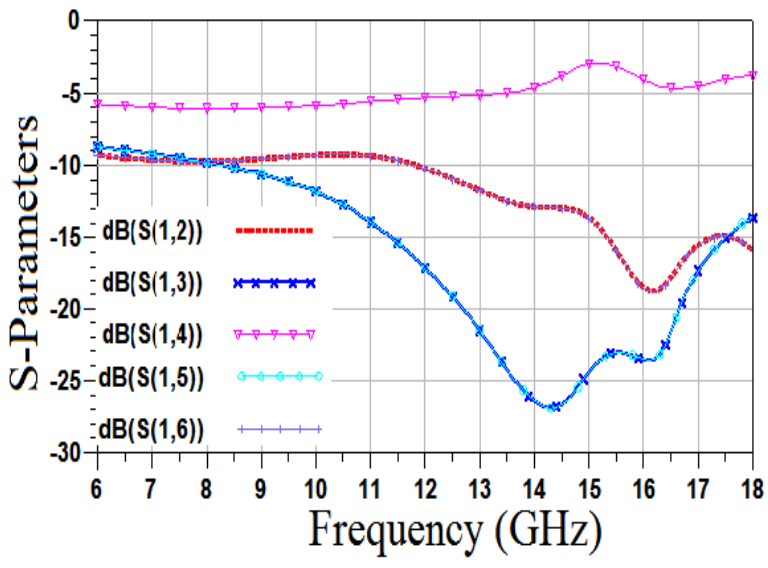

Fig. 9: Insertion Loss of the Proposed Design.

\section{Conclusion}

Unequal five way Wilkinson power divider for EW Applications is designed and simulated making use of 3-way Wilkinson power divider and 2-way Wilkinson power divider. The design makes use of low cost and easily available FR4 substrate. The whole design is compact in size with $11 \mathrm{~mm} \times 33 \mathrm{~mm} \times 1.5 \mathrm{~mm}$ as overall area. The results obtained

\section{References}

[1] Wilkinson, E. J. (1960). "An N-way hybrid power divider.” IRE Transactions on Microwave Theory and Techniques, 8(1), 116-118. https://doi.org/10.1109/TMTT.1960.1124668.

[2] L. I. Parad and R. L. Moynihan, "Split-tee power divider," IEEE Trans. Microwave Theory and Techniques, vol. MTT-13, pp. 91-95, January 1965. https://doi.org/10.1109/TMTT.1965.1125934.

[3] S.B. Cohn, "A class of broadband three-port TEM-mode hybrids, "IRE Trans. Microwave Theory Tech., vol. MTT-16, no.2,pp. 110 116. Feb1968. https://doi.org/10.1109/TMTT.1968.1126617.

[4] DimitriosAntsos, Rick Crist and Lin Sukamto. "A Novel Wilkinson Power Divider with Predictable Performance At K And Ka-Band". IEEE Conference 2002.

[5] Maktoomi, M. A., Hashmi, M. S., \&Ghannouchi, F. M. (2016) Theory and Design of a Novel Wideband DC Isolated Wilkinson Power Divider. IEEE Microwave and Wireless Components Letters, 26(8), 586-588. https://doi.org/10.1109/LMWC.2016.2585572.

[6] L. Wu, Z. Sun, H. Yilmaz, and M. Berroth, “A dual-frequency Wilkinsonpower divider," IEEE Trans. Microw. Theory Techn., vol 54 , no. 1, pp. 278284, Jan. 2006

[7] X. Wang, I. Sakagami, K. Takahashi, and S. Okamura, “A generalized dual-band Wilkinson power divider with parallel L, C, and R components,"IEEE Trans. Microw. Theory Techn., vol. 60, no. 4, pp. 952964, Apr. 2012 https://doi.org/10.1109/TMTT.2012.2184298.

[8] X. Wang, I. Sakagami, Z. Ma, A. Mase, M. Yoshikawa, and M. Ichimura, 'Miniaturized dual-bandWilkinson power divider with self-compensationstructure," IEEE Trans. Compon., Packag., Manuf. Technol., vol. 5, no. 3, pp. 389397, Mar. 2015.
[9] P. V. Naidu, V. Ravi and A. Kumar, "A novel compact unequal wideband Wilkinson power divider for UWB and EW applications," 2017 Progress in Electromagnetics Research Symposium Fall (PIERS - FALL), Singapore, 2017, pp. 737-742. https://doi.org/10.1109/piers-fall.2017.8293232

[10] Vummadisetty, P. N., \& Kumar, A. "Compact Uniplanar Multi Feed Multi Band ACS Monopole Antenna Loaded With Multiple Radiating Branches for Portable Wireless Devices". Advanced Electromagnetics, Vol. 7, No.2, (2018), pp.68-75. https://doi.org/10.7716/aem.v7i2.661

[11] Naidu, P. V., \& Kumar, A. "ACS-fed e-shaped dual band uniplanar printed antenna for modern wireless communication applications". Radioelectronics and Communications Systems, Vol. 61, (2018), pp. 87-93. https://doi.org/10.3103/S0735272718030019

[12] Naidu, P. V., Kumar, A., \& Kumar, V. "Uniplanar Y and L shaped ACS fed multiband and wideband compact printed antenna for advanced wireless communication systems". Microsystem Technologies, Vol. 24, No.4, (2018), pp.2051-2061. https://doi.org/10.1007/s00542-017-3606-3.

[13] Vummadisetty, P. N., \& Kumar, A. "Multi feed multi band uniplanar ACS fed antenna with $\mathrm{N}$ shape and inverted L shape radiating branches for wireless applications". Microsystem Technologies, Vol. 24, No.4, (2018), pp.1863-1873 https://doi.org/10.1007/s00542-017-3565-8.

[14] Kumar, A., Naidu, P. V., \& Kumar, V. "A compact uniplanar ACS fed multi band low cost printed antenna for modern $2.4 / 3.5 / 5 \mathrm{GHz}$ applications". Microsystem Technologies, Vol. 24, No.3, (2018), pp 1413-1422. https://doi.org/10.1007/s00542-017-3556-9.

[15] Naidu, P. V., Kumar, A., \& Rajkumar, R. "Design, analysis and fabrication of compact dual band uniplanar meandered ACS fed antenna for 2.5/5 GHz applications". Microsystem Technologies, pp.1-8. (2018). https://doi.org/10.1007/s00542-018-3937-8.

[16] Kumar, A., Naidu, P. V., Kumar, V., \& Ramasamy, A. K. "Design $\&$ Development of compact uniplanar semi-hexagonal ACS fed multi-band antenna for portable system application". Progress in Electromagnetics Research, Vol. 60, (2017), pp.157-167. https://doi.org/10.2528/PIERM17080302.

[17] Naidu, P. V., \& Kumar, A. "Design and development of triple band ACS fed antenna with $\mathrm{M}$ and rectangular shaped radiating branches for $2.45 / 5 \mathrm{GHz}$ wireless applications". Microsystem Technologies, Vol. 23, No.12, (2017), pp.5841-5848 https://doi.org/10.1007/s00542-017-3430-9.

[18] Colin, J-M. "Phased array radars in France: Present and future." Phased Array Systems and Technology, 1996. IEEE International Symposium on. IEEE, 1996.

[19] Chou, Hsi-Tseng, and Hao-Ju Huang. "Multilevel Subarray Modularization to Construct Hierarchical Beamforming Networks for Phased Array of Antennas with Low Complexity." IEEE Transactions on Antennas and Propagation 65.11 (2017): 5819-5828. https://doi.org/10.1109/TAP.2017.2751657.

[20] Naidu, P. V. "Printed V-shape ACS-fed compact dual band antenna for bluetooth, LTE and WLAN/WiMAX applications". Microsystem Technologies, Vol. 23, N0.4, (2017), pp.1005-1015 https://doi.org/10.1007/s00542-016-2939-7

[21] Naidu, P. V., \& Kumar, A. "A novel ACS fed multi band antenna loaded with mirrored $\mathrm{S}$ and $\mathrm{L}$ shaped strips for advanced portable wireless communication applications". Microsystem Technologies, Vol. 23, No.10, (2017), pp. 4775-4783 https://doi.org/10.1007/s00542-017-3313-0.

[22] Naidu, P. V., \& Malhotra, A. "Design \& analysis of miniaturized asymmetric coplanar strip fed antenna for multi-band WLAN/WiMAX applications". Progress in Electromagnetics Research, Vol. 57, (2015), pp. 159-171. https://doi.org/10.2528/PIERC15042302.

[23] Naidu, P. V., \& Kumar, R. "Design of a compact ACS-fed dua band antenna for Bluetooth/WLAN and WiMAX applications". Progress in Electromagnetics Research, Vol. 55, (2014), pp. 63-72. https://doi.org/10.2528/PIERC14101803.

[24] Naidu, P. V. "Design, simulation of a compact triangular shaped dual-band Microstrip antenna for $2.4 \mathrm{GHz}$ bluetooth/WLAN and UWB Applications". Wireless Personal Communications, Vol. 95, No.2, (2017), pp.783-794. https://doi.org/10.1007/s11277-0163798-3.

[25] Kumar, R., Naidu, V. P., Kamble, V., \& Krishna, R. R. "Simulation, design of compact multi-band microstrip slot antennas for WiMAX/WLAN and UWB applications". Wireless Personal Communications, Vol. 80, No.3, (2015), pp. 1175-1192. https://doi.org/10.1007/s11277-014-2079-2.

[26] Naidu, P. V., \& Kumar, R. "A Compact Dual-Band Octagonal Slotted Printed Monopole Antenna for WLAN/ WiMAX and UWB 
Applications". Journal of Microwaves, Optoelectronics and Electromagnetic Applications, (2015), 14(1), 1-13. https://doi.org/10.1590/2179-10742015v14i1422.

[27] Kumar, R., Naidu, P. V., \&Kamble, V. "Design of Asymmetric Slot Antenna with Meandered Narrow Rectangular Slit for Dual Band Applications". Progress in Electromagnetics Research B, (2014), 60, 111-123. https://doi.org/10.2528/PIERB14042205.

[28] Naidu, P. V., Kumar, A., \& Kumar, V. "A miniaturized triple band ACS-fed monopole printed antenna with meandered and circular ring shape resonators for WLAN/WiMAX applications".2017 Progress in Electromagnetics Research Symposium Fall (PIERS FALL), pp. 1933-1937. $\quad$ https://doi.org/10.1109/PIERSFALL.2017.8293454.

[29] Naidu, P. V., Kumar, A., \& Kumar, V. "A very small wideband asymmetric coplanar strip fed printed dual band antenna for advanced communication applications".2017 Progress in Electromagnetics Research Symposium Fall (PIERS - FALL), pp. 1928-1932. https://doi.org/10.1109/PIERS-FALL.2017.8293453.

[30] Naidu, P. V., \& Kumar, A. "ACS-fed multiband antenna loaded with staircase radiating strips for wireless communication systems".2017 Progress in Electromagnetics Research Symposium Fall (PIERS - FALL), pp. 26-30. https://doi.org/10.1109/PIERSFALL.2017.8293105.

[31] Naidu, P. V., Kumar, A., \& Kumar, V. (2017). "Simulation of meandered uniplanar printed antenna for multiband applications".2017 Progress in Electromagnetics Research Symposium - fall (PIERS FALL), pp. 1938-1941. $\quad$ https://doi.org/10.1109/PIERSFALL.2017.8293455.

[32] Kumar, A., Naidu, P. V., \& Kumar, V. (2017). "A novel rhombus shaped ACS fed multi band antenna loaded with meander branches for advanced communication applications" 2017 Progress in Electromagnetics Research Symposium - fall (PIERS - FALL), pp. 724 730. https://doi.org/10.1109/PIERS-FALL.2017.8293230.

[33] Kumar, A., \& Naidu, P. V. (2016) "A compact O-shaped printed ACS fed monopole dual-band antenna for $2.4 \mathrm{GHz}$ Bluetooth and 5GHz WLAN/WiMAX applications". 2016 Progress in Electromagnetic Research Symposium (PIERS), pp. 2004-2008. https://doi.org/10.1109/PIERS.2016.7734856.

[34] Kumar, A., \& Naidu, P. V. (2016). "A novel compact printed ACS fed dual-band antenna for Bluetooth/WLAN/WiMAX applications". 2016 Progress in Electromagnetic Research Symposium (PIERS), pp. 2000-2003. https://doi.org/10.1109/PIERS.2016.7734855.

[35] Naidu, P. V., \&Malhotra, A. "A small ACS-fed tri-band antenna employing $\mathrm{C}$ and $\mathrm{L}$ shaped radiating branches for LTE/WLAN/WiMAX/ITU wireless communication applications. Analog Integrated Circuits and Signal Processing, (2015), 85(3), 489-496. https://doi.org/10.1007/s10470-015-0637-5.

[36] Naidu, P. V., \& Kumar, R. "A very small asymmetric coplanar strip fed multi-band antenna for wireless communication applications". Microsystem Technologies, (2015), 22(9), 2193-2200. https://doi.org/10.1007/s00542-015-2613-5.

[37] Naidu, P. V., Malhotra, A., \& Kumar, R. “A compact ACS-fed dual-band monopole antenna for LTE, WLAN/WiMAX and public safety applications". Microsystem Technologies, (2015), 22(5), 1021-1028. Doi: 10.1007/s00542-015-2562-z. https://doi.org/10.1007/s00542-015-2562-z.

[38] Kumar, R., Naidu V, P., \&Kamble, V. "A compact asymmetric slot dual band antenna fed by CPW for PCS and UWB applications". International Journal of RF and Microwave Computer-Aided Engineering, (2014), 25(3), 243-254. doi:10.1002/mmce.20855. https://doi.org/10.1002/mmce.20855.

[39] Vummadisetty, P. N., \& Kumar, R. (2016). "Design of compact octagonal slotted hexagonal and rectangular shaped monopole antennas for dual/UWB applications". Turkish Journal of Electrical Engineering \& Computer Sciences, 24, 2806-2824. https://doi.org/10.3906/elk-1404-174.

[40] Naidu, V. P., \& Kumar, R. (2014). Design of Compact DualBand/Tri-Band CPW-Fed Monopole Antennas for WLAN/WiMAX Applications. Wireless Personal Communications, 82(1), 267-282. https://doi.org/10.1007/s11277-014-2207-z.

[41] Naidu, P. V., \& Kumar, R. "Design of Cpw-Fed Dual-Band Printed Monopole Antennas for Lte/Wimax/Wlan and Uwb Applications". Progress in Electromagnetics Research C, (2014), 54, 103-116. https://doi.org/10.2528/PIERC14071006. 